\title{
Michelangelo Buonarotti
}

\section{Bodybuilder mit Aufbauplastik}

\author{
Als Michelangelos Plastik der Öffentlichkeit erstmals zugänglich gemacht wurde, heftete \\ ein unbekannter Zeitgenosse einen Zettel mit folgendem Vers an die Skulptur: „Die Nacht, \\ die du reizend hier schlummern siehst, ist von einem Engel in Marmor gehauen worden." \\ Der Engel ist dabei nicht nur ein Kompliment an, sondern auch ein hübsches Wortspiel \\ mit dem Namen Michelangelo. Doch bei aller Verehrung für das Renaissance Genie: Die \\ Begeisterung will sich heute nicht mehr so recht einstellen. Denn richtig "reizend" ist \\ diese weibliche Marmor-Nacht ja nicht.
}

$\mathrm{M}$ an schaue sich nur einmal die Muskulatur des rechten Armes und des linken Oberschenkels an. Unwillkürlich stellt sich hier die Frage: War Anabolikamissbrauch bereits im 16. Jahrhundert verbreitet? Und das bei Frauen? Auch die Brüste sehen eher aus wie schlechte, weil viel zu lateral und unnatürlich platzierte Aufbauplastiken. Ein ästhetischer Chirurg würde angesichts eines solchen Operationsergebnisses wohl seine Haftpflichtversicherung informieren müssen.

Es bleibt also ein Rätsel: Wieso formt das Bildhauergenie der italienischen Renaissance solche weiblichen Körper? An kunsthistorischen Erklärungs- und Ehrenrettungsversuchen mangelt es nicht. Einer lautet folgendermaßen: Es handelt sich nicht um ein Frauenporträt, sondern um eine allegorische Darstellung. Die „Nacht“ sei besonders muskulös und kraftvoll dargestellt, um zu zeigen, welch ungeheuere Energie in ihr schlummert. Schön und gut. Nur leider sehen fast alle anderen Frauendarstellungen Michelangelos genauso aus: ob die großformatigen Sibyllen in der Sixtinischen Kapelle oder Frauenakte als intime Rötelzeichnungen - lauter weibliche Muskelprotze.

Und schon eilen feministisch gesinnte Kunsthistorikerinnen zu Hilfe. Frauen, so behaupten sie, seien in der Kunst der damaligen Zeit überwiegend sanft, nachgiebig, kraftlos und sinnenfreudig dargestellt worden. Michelangelo habe dagegen versucht, sie dem Mann ebenbürtig zu zeigen: nämlich stark und daher auch muskulös. Michelangelo als ein sehr früher Vertreter der Frauenbewegung? Das wohl eher nicht.

Wahrscheinlich ist die Lösung des Problems eher banal. Frauen haben Michelangelo ganz einfach nicht interessiert. Beruflich nicht und privat erst recht nicht. Genau wie das zweite Universalgenie der italienischen Renaissance, Leonardo da Vinci, war Michelangelo homosexuell. Der männliche Körper faszinierte ihn. Ihm widmete er seine ganze Aufmerksamkeit und seine ungeheuere Schaffenskraft. Miche-

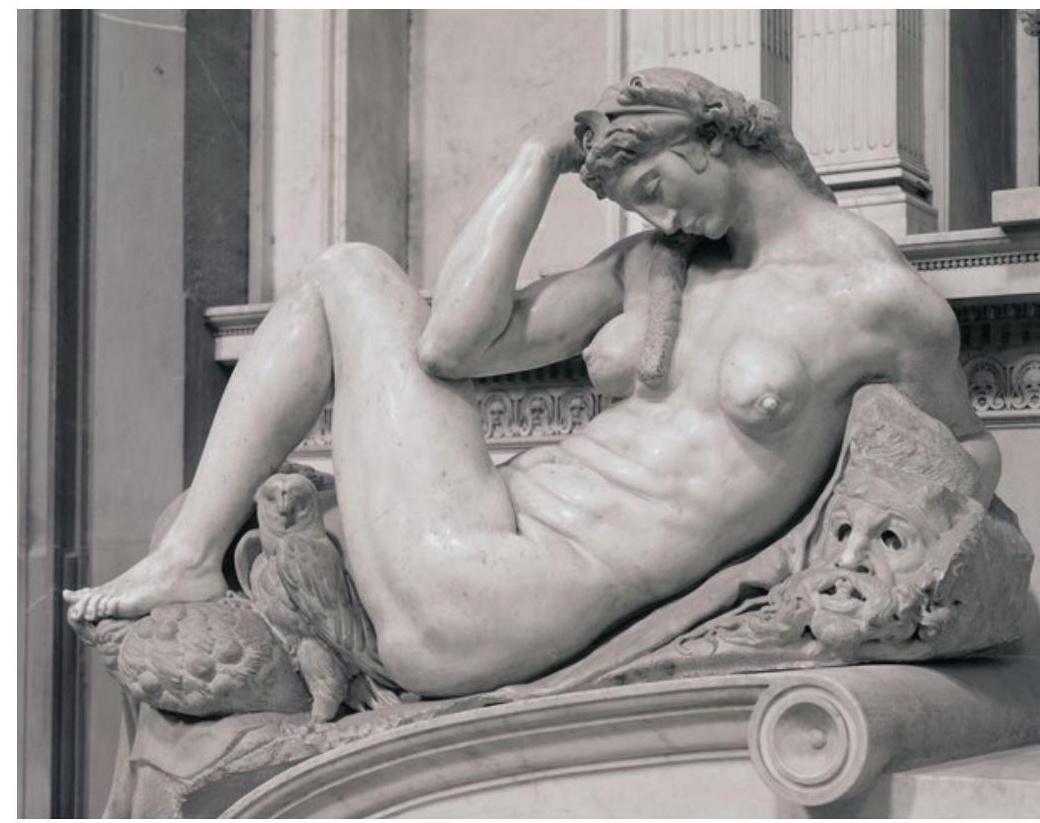

„Die Nacht", Marmor, 1526, Michelangelo Buonarotti (1475-1564)

langelos übergroße Skulptur des David ist auch nach 500 Jahren noch die Darstellung des perfekten männlichen Körpers schlechthin.

Mit Frauengestalten gab sich Michelangelo dagegen nur wenig Mühe. Da montierte er einfach ein paar Brüste auf einen Männerkörper. Genies dürfen das. Wer mit der Ausmalung der Sixtinischen Kapelle das wohl größte Kunstwerk der Menschheitsgeschichte geschaffen hat, dem lässt man auch ein paar weibliche Bodybuilder mit missratenen Titten durchgehen.

Prof. Dr. med. Bernd Kleine-Gunk, Fürth 